\title{
Retrospective Study in Primary Central Nervous System Lymphoma: The Impact of Treatment Strategies of the Last 20 Years
}

\author{
Omar F Iskanderani ${ }^{1,2 *}$ \\ ${ }^{1}$ Department of Radiotherapy, Faculty of Medicine, King Abdulaziz University, Saudi Arabia
}

${ }^{2}$ Radiation Oncology Department, Faculty of Medicine, Institut Claudius Regaud, France

Submission: July 21, 2018; Published: August 21, 2018

"Correspondence Address: Omar F Iskanderani, Department of Radiation Oncology, Faculty of medicine King Abdulaziz University, P.O. Box: 80200, Zip Code: 21589, Jeddah, Kingdom of Saudi Arabia, Tel: +966555556995; Email: kadroos@hotmail.com

\begin{abstract}
HPrimary central nervous system lymphoma (PCNSL) is an uncommon malignant syndrome, appearing more frequently with old ages patients. In the last decade, serious modifications in the treatments approaches were done. This is a retrospective review to asses these modifications in our practice and their effect on prognosis over a 17-year time period. We reviewed the patient radiological data and histopathology of all patients diagnosed with this disease (according to the neuropathological registry) at Toulouse University Hospital and Institut Claudius Regaud between 1995-2012. 78 patients were included (44 females, 34 males) with Karnofsky Performance Status (KPS) score of median 80\%. The patient age groups ranged between (25-86 years) and the rate of overall survival was 23.1 months. Within routine practice, we observed modifications in the therapeutic strategy for this disease in the last decade and improvements in the dealing with managements; the treatment used in the medical oncology spicily in chemotherapy were changed, and radiotherapy is not common used as first-choice treatment. This study from our data, emphasizing the need for a prospective study investigating therapeutic strategies for this kind of disease (PCNSL), especially in elderly patients.
\end{abstract}

Keywords: (PCNSL); Radiotherapy; Lymphoma; High dose methotrexate; WBRT

\section{Introduction}

The most important risk factor for primary central nervous system lymphoma (PCNSL) development is immunodeficiency [1-7]. PCNSL was traditionally treated with cranial irradiation, i.e., whole-brain radiotherapy (WBRT). WBRT may become complicated by the development of chronic and late neurotoxicity. Treatment with chemotherapy alone was suggested to avoid such complications. The ideal treatment of PCNSL is poorly demarcated. The use of wide variety of methotrexate (MTX) based treatment regimens resulted in excellent survival rates. Nevertheless, disease control with these regimens is unpredictable.

PCNSL is a diffuse disease, partial or complete surgical removal provides minimal benefit with a median survival of 1-5 months with surgery alone. Radiation therapy up to $45 \mathrm{~Gy}$ has been considered as the standard treatment till mid-1990s. A prospective trial treated patients with a 40 Gy WBRT and 20 Gy boost to the gross tumor demonstrated similar results to previously reported studies. The median survival was 1 year and $28 \%$ of the patients survived 2 years [8]. Despite high radiation doses used, $92 \%$ of patients had brain recurrence. Although more than $50 \%$ of patients achieved an initial complete response (CR) after WBRT, recurrences were frequent with an overall survival of $12-18$ months. In the late 1970s, treatment strategies for PCNSL started to change.

A study by Ervin \& Canellos [9] demonstrated the remarkable efficacy of high dose MTX plus leucovorin in the treatment of recurrent CNS lymphomas. Brain large-cell lymphoma has roughly twofold sensitivity to the high dose MTX compared to histologically similar systemic type [10]. A study performed in France tried a chemotherapy regimen used for the treatment of pediatric Burkett lymphomas (CR5 protocol). The regimen involved four chemotherapy courses with high dose MTX and cytarabine followed by brain radiation. The CR was $56 \%$ and the 5-years overall survival was 56\%. However, high toxicity rate was reported in patients over 60 years of age [11]. That is attributed to the fact that the median age of PCNSL patients is approximately 56 years in most series, as well as to age-related treatment-induced neurotoxicity likely being a continuous variable.

It has been established that the majority of PCNSL patients will experience a significant delayed radiation injury from standard WBRT. In an attempt to avoid such toxicity, a reduction approach has been applied aiming to maximize the efficacy of repeat cycles of high dose MTX as a monotherapy. This approach 


\section{Cancer Therapy \& Oncology International Journal}

has proven long-term survival rates similar to that achieved with combined modality treatment. The incidence of PCNSL is increasing in patient population $>65$ years old. This group is most vulnerable to the delayed radiation toxicity. Hence, high dose MTX monotherapy has been used for many years for induction and relapse with significant efficacy [11,12-15]. Furthermore, a randomized control trial by Thiel et al. [16] proved that the overall survival was not affected after omitting the standard dose WBRT as a consolidation therapy after MTX induction. PCNSL was considered rare; thus, the optimum management of patients with this disease remains to be established. The increased incidence of PCNSL and the recognition that radiotherapy often produced a dramatic response associated with rapid relapse have led to the continued investigation of improved therapies for PCNSL over the past 20 years. The mortality associated with delayed neurotoxicity in patients receiving both chemotherapy and WBRT has led to comparable survival rates, irrespective of whether WBRT is used or not $[17,18]$.

\section{Purpose}

In this article, we aimed to evaluate the change in therapeutic approaches in PCNSL in routine practice and the subsequent improvements in survival over a 15 -year period. The impact of patient age on both the choice of therapeutic strategy and survival was also analyzed to evaluate our treatment strategies before and after 2003.

\section{Study Design}

This study employed a retrospective multicenter design.

\section{Eligibility \\ Eligibility criteria}

Patients histologically diagnosed with PCNSL confined to the brain, and individuals aged 20-86 years were included in this study. There were no inclusion limitations related to the Eastern Cooperative Oncology Group (ECOG) performance score. The exclusion criterion included lymphoma that developed outside the brain.

\section{Patients and Methods}

This is a retrospective study in which 82 patients diagnosed with PNCSL were included, and where a bicentric retrospective study was performed at the Institut Claudius Regaud and the University Hospital of Toulouse. Before 2003 the median patient age was 65 years, while after 2003 it was 64.5 years. The male-to-female ratio is $1: 2$. The clinical and survival data of all patients registered with a diagnosis of PCNSL during the period spanning January 5, 1995 to December 28, 2012 were reviewed. The patients were selected using neuropathological data, as well as based on data obtained from the hospital data system. We included all adult patients with a histopathological diagnosis of primary cerebral lymphoma and without associated systemic lymphoma. Age, gender, performance status, and treatment modalities (during first-line treatment and at recurrence) were examined. Progression-free survival and OS were assessed using Kaplan-Meier methodology and calculated from the beginning of treatment. This analysis was also conducted for patients treated before or after 2003, and with patients above and below 60 years of age (Table 1).

Table 1: General patient characteristics $(n=76)$.

\begin{tabular}{|c|c|c|c|}
\hline Characteristics & $\begin{array}{c}\text { All }(n=76) N \\
(\%)\end{array}$ & $\begin{array}{l}<2003(\mathrm{n}= \\
36) \times(\%)\end{array}$ & $\begin{array}{c}>2003(n= \\
40) N(\%)\end{array}$ \\
\hline \multicolumn{4}{|l|}{ Age at Diagnosis } \\
\hline$<60$ years & 32 (42.15\%) & $16(44.44 \%)$ & $16(40.00 \%)$ \\
\hline $60-70$ years & $15(19.70 \%)$ & $6(16.66 \%)$ & $9(22.50 \%)$ \\
\hline$>70$ years & 29 (38.15\%) & $14(38.88 \%)$ & $15(37.50 \%)$ \\
\hline \multicolumn{4}{|l|}{ Sex } \\
\hline Male & 35 (46.05\%) & 17 (47.22\%) & $18(45.00 \%)$ \\
\hline Female & 41 (53.94\%) & 19 (52.77\%) & $22(55.00 \%)$ \\
\hline \multicolumn{4}{|l|}{ Histology Type } \\
\hline B-Cell & 74 (97.36\%) & $36(100.00 \%)$ & $38(95.00 \%)$ \\
\hline Other & $2(2.63 \%)$ & $0(0.00 \%)$ & $2(5.00 \%)$ \\
\hline \multicolumn{4}{|l|}{ Patient Status } \\
\hline $0-2$ & $51(67.10 \%)$ & $16(44.44 \%)$ & $35(87.50 \%)$ \\
\hline $3-4$ & 25 (32.90\%) & $20(55.55 \%)$ & $5(12.50 \%)$ \\
\hline
\end{tabular}

\section{Treatment Strategy}

Two different treatment strategies were applied: the first was employed before 2003, in which no $(0 \%)$ patients received firstline chemotherapy, $10(27.8 \%)$ patients received concomitant chemotherapy plus radiotherapy, and 26 (72.2\%) patients were treated with radiotherapy alone. The second strategy was employed after 2003, in which 17 (42.5\%) patients received firstline chemotherapy, 19 (47.5\%) patients received concomitant chemotherapy plus radiotherapy, and $4(10 \%)$ patients received radiotherapy alone. Details of the chemotherapy protocols are shown in Table 2. It can be observed that the use of radiotherapy was modified after 2003. All 36 (100\%) patients who were treated before 2003 received radiotherapy, while only 23 (57.5\%) patients were treated with radiotherapy after 2003. First-line treatments are shown in Table 3. To study the effect of age, the patients were further subdivided into two groups: those below the age of 60 years and those above. The characteristic and first-line therapeutic strategies are presented in Table 4.

Table 2: Comparison of the first-line therapeutic strategies employed before and after 2003.

\begin{tabular}{|c|c|c|c|}
\hline & All (N=76) & $\mathbf{< 2 0 0 3} \mathbf{( N = 3 6 )}$ & $\mathbf{> 2 0 0 3} \mathbf{( N = 4 0 )}$ \\
\hline Chemotherapy & $17(22.36 \%)$ & $0(0.00 \%)$ & $17(42.50 \%)$ \\
\hline $\begin{array}{c}\text { Chemotherapy- } \\
\text { radiotherapy } \\
\text { concomitant }\end{array}$ & $29(38.15 \%)$ & $10(27.77 \%)$ & $19(47.50 \%)$ \\
\hline Radiotherapy & $30(39.47 \%)$ & $26(72.22 \%)$ & $4(10.00 \%)$ \\
\hline $\begin{array}{c}\text { Second-line } \\
\text { Chemotherapy }\end{array}$ & $18(23.68 \%)$ & $5(13.88 \%)$ & $13(23.50 \%)$ \\
\hline Yes & $58(76.31 \%)$ & $31(86.11 \%)$ & $27(67.50 \%)$ \\
\hline No & & & \\
\hline
\end{tabular}




\section{Cancer Therapy \& Oncology International Journal}

Table 3: Chemotherapy protocols.

\begin{tabular}{|c|c|c|c|}
\hline & All (N = 76) & $\begin{array}{c}<2003(\mathrm{~N}= \\
36)\end{array}$ & $\begin{array}{c}>2003(\mathrm{~N}= \\
40)\end{array}$ \\
\hline \multicolumn{4}{|l|}{ Chemotherapy } \\
\hline Yes & 46 (60.52\%) & $10(27.8 \%)$ & $36(90 \%)$ \\
\hline No & 30 (39.47\%) & $26(72.2 \%)$ & $4(10 \%)$ \\
\hline \multicolumn{4}{|l|}{$\begin{array}{c}\text { Chemotherapy } \\
\text { Type }\end{array}$} \\
\hline MTX alone & $2(4.34 \%)$ & $1(10.00 \%)$ & $1(2.77 \%)$ \\
\hline MTX + Others & $42(91.30 \%)$ & $8(80.00 \%)$ & $34(94.44 \%)$ \\
\hline $\begin{array}{l}\text { Others without } \\
\text { MTX }\end{array}$ & $2(4.34 \%)$ & $1(10.00 \%)$ & $1(2.77 \%)$ \\
\hline \multicolumn{4}{|l|}{$\begin{array}{c}\text { Chemotherapy } \\
\text { Protocol }\end{array}$} \\
\hline CHOP & $2(4.34 \%)$ & $2(20.00 \%)$ & $0(0.00 \%)$ \\
\hline COP & $1(2.17 \%)$ & $1(10.00 \%)$ & $0(0.00 \%)$ \\
\hline COPADEM & 7 (15.21\%) & $2(20.00 \%)$ & $5(13.88 \%)$ \\
\hline MTX High Dose & $4(8.69 \%)$ & $2(20.00 \%)$ & $2(5.55 \%)$ \\
\hline $\begin{array}{c}\text { MTH High Dose } \\
+ \text { MTZ }\end{array}$ & $6(13.04 \%)$ & $0(0.00 \%)$ & $6(16.66 \%)$ \\
\hline Others & 26 (56.52\%) & $3(30.00 \%)$ & $23(63.88 \%)$ \\
\hline
\end{tabular}

MTX: Methotrexate; CHOP: Cyclophosphamide, hydroxydaunorubicin (doxorubicin), vincristine (Oncovin ${ }^{\circledR}$ ), and prednisone; COP Cyclophosphamide, vincristine (Oncovin ${ }^{\circledR}$ ), and prednisolone; COPADEM: cyclophosphamide, vincristine (Oncovin $\left.{ }^{\circledR}\right)$, prednisolone, doxorubicin (Adriamycin), methotrexate; MTH: Newcastle disease virus vaccine (MTH-68/H); MTZ: mitoxantrone.

Table 4: Patient characteristics depending on age.

\begin{tabular}{|c|c|c|}
\hline & $\begin{array}{c}\text { Below } 60 \text { years }(\mathrm{N} \\
=32)\end{array}$ & $\begin{array}{c}\text { Over } 60 \text { years }(\mathrm{N} \\
=44)\end{array}$ \\
\hline \multicolumn{3}{|l|}{ Age at Diagnosis } \\
\hline Median & 48.00 & 74.00 \\
\hline Range & $20.00-59.00$ & $61.00-86.00$ \\
\hline \multicolumn{3}{|l|}{$\begin{array}{l}\text { Patient Status } \\
\text { (OMS) }\end{array}$} \\
\hline $0-2$ & $23(71.87 \%)$ & 28 (63.63\%) \\
\hline $3-4$ & $9(28.12 \%)$ & $16(36.36 \%)$ \\
\hline Chemotherapy & $5(15.62 \%)$ & $12(27.27 \%)$ \\
\hline $\begin{array}{l}\text { Chemo-Radio } \\
\text { Concentration }\end{array}$ & $17(53.12 \%)$ & $12(27.27 \%)$ \\
\hline Radiotherapy & $10(31.25 \%)$ & $20(45.45 \%)$ \\
\hline \multicolumn{3}{|l|}{$\begin{array}{c}\text { Second-line } \\
\text { Chemotherapy }\end{array}$} \\
\hline Yes & $12(37.50 \%)$ & $6(13.63 \%)$ \\
\hline No & $20(62.50 \%)$ & 38 (86.36\%) \\
\hline
\end{tabular}

\section{Results}

Eighty-two patients were included in this study, of which 46 (56\%) were females and 36 (44\%) were males. Among them, 6 patients did not receive any treatment, i.e., exclusive supportive care. The patients' characteristics are listed in Table 1. Ninetyseven percent of patients had a form of B-cell lymphoma. The median Karnofsky Performance Status (KPS) score was 80\%, and the patients' median age was 65 years (20-86 years). Twothirds of the patients were above 60 years of age, and around $40 \%$ were above 70 years of age. Thirty-six patients were treated between 1995 and 2003, while 40 patients were treated between 2003 and 2012 .

Seventy-six patients met the eligibility criteria for our study; 36 patients were treated before 2003 and 40 patients were treated after 2003. When focusing on the modifications in strategies employed before and after 2003, we can observe that before 2003, first-line chemotherapy was administered in none of the patients (0\%) vs. $42.5 \%$ after 2003. Furthermore, chemotherapy concomitant with radiotherapy was delivered to $27.8 \%$ of the patients before 2003 vs. $47.5 \%$ after 2003 . Finally, radiotherapy was employed in $100 \%$ of patients before 2003 vs. $57.5 \%$ after.

The primary endpoint of this study was the estimation of OS, which was established as 23.1 months. The median time to progression was 19.2 months, while the median OS at follow-up was 41.0 months. Further details of the patients' response to therapy are as follows:

i. A complete response was observed in fifteen (41.7\%) patients after 2003 vs. zero (0\%) patients before 2003 .

ii. Partial response was observed in sixteen (44.4\%) patients after 2003 vs. seven (70\%) patients before 2003 .

iii. Stable disease was observed in four (11\%) patients after 2003 vs. one (10\%) patient before 2003.

iv. Progression was observed in one $(2.8 \%)$ patient after 2003 vs. two (20\%) patients before 2003.

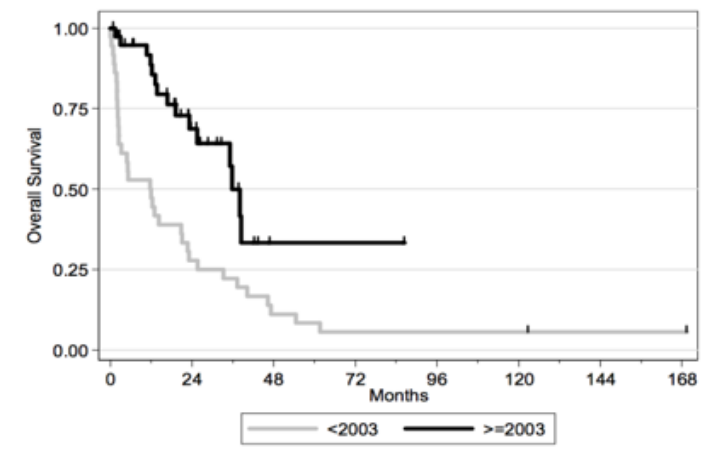

Figure 1: General overall survival $(P=0.0003)$.

Therefore, we can conclude that transitioning from radiotherapy to chemotherapy as the first-choice treatment yields better results. The figures illustrate the general OS and the general time to progression in all populations examined in our study, as shown in Figures 1 \& 2. Figures 3-6 show the OS for patients over 60 years old vs. those below 60 years old, and the time to progression for patients over 60 years old vs. those younger than 60 years old. 


\section{Cancer Therapy \& Oncology International Journal}

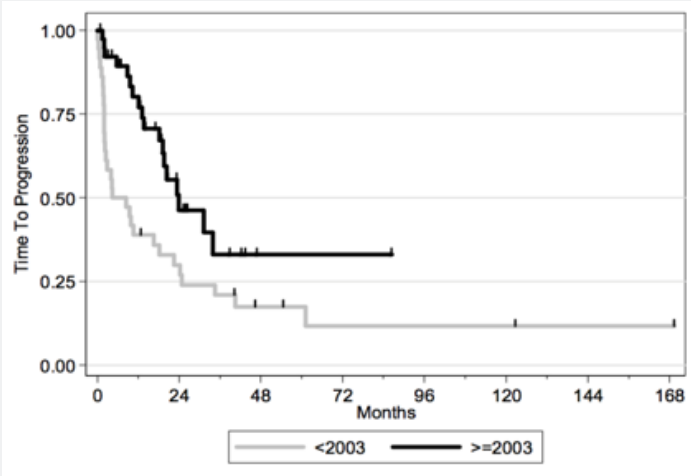

Figure 2: General time to progression $(P=0.0060)$.

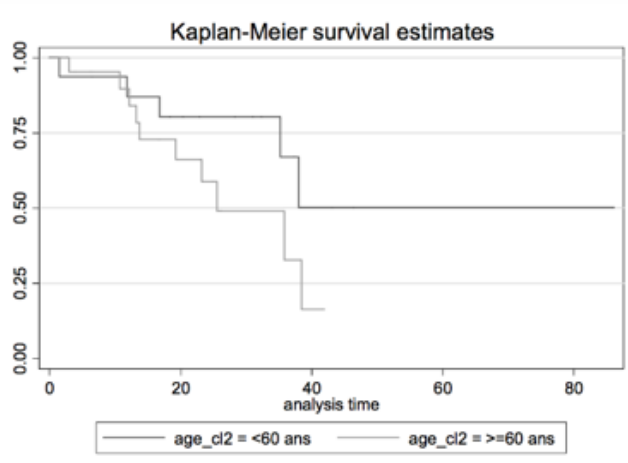

Figure 3: Overall survival after $2003(P=0.1395)$.

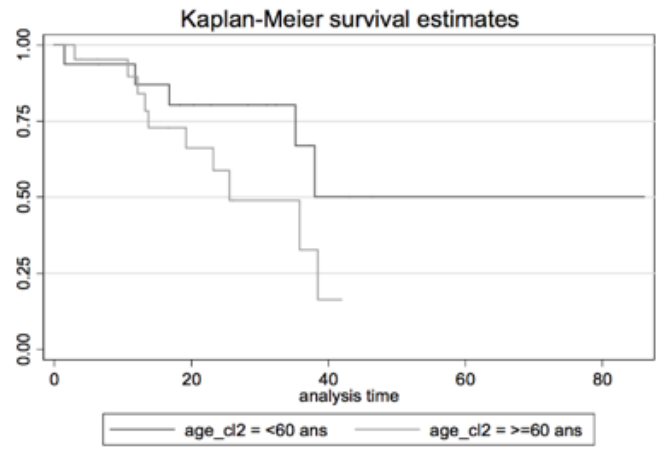

Figure 4: Time to progression after $2003(P=0.5601)$.

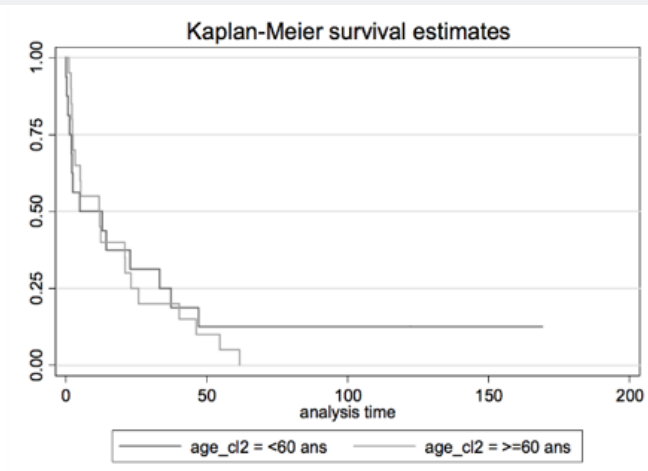

Figure 5: Overall survival before $2003(P=0.6700)$.

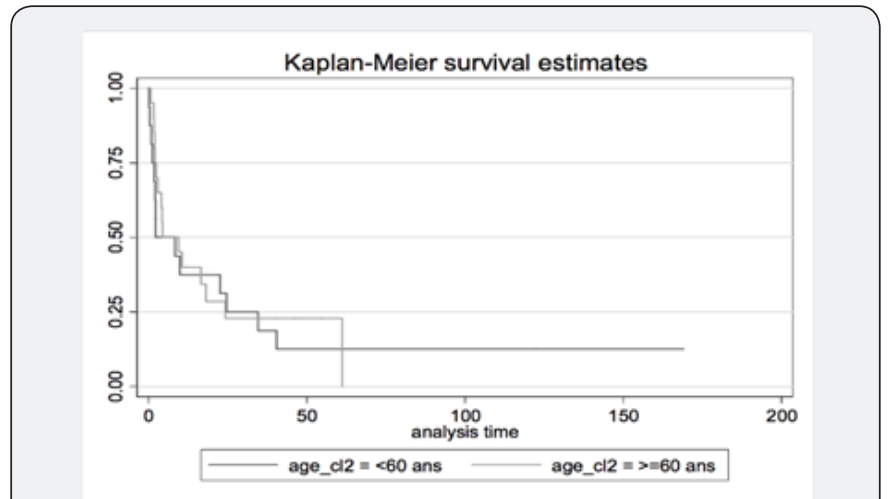

Figure 6: Time to progression before $2003(P=0.7380)$.

\section{Discussion}

The optimal management for adults newly diagnosed with PCNSL is still controversial $[19,20]$. This debate largely reflects the paucity of multi-institutional trials and the relative failure of WBRT without chemotherapy as an initial treatment for PCNSL, which is associated with a median survival of 11.6 months, as demonstrated in the multicenter RTOG-8315 trial [9,21]. In addition, the late neurotoxic consequences of WBRT, such as cognitive impairment, are especially prevalentable, particularly in patients over 60 years of age; this is so important since most patients with PCNSL are typically of advanced age [17,22-24].

Another studies by Miller et al. [5], DeAngelis [25], Abrey [17], and Batchelor [22], provided the first choice of treatment which included HD-MTX in most treatment regimens for PCNSL $[17,24,26,27]$. For instance, Batchelor [22] reported on the combined complete response in (52\%) and partial response in $(22 \%)$ rate to single-agent HD-MTX, demonstrating its efficacy, however, Herrlinger [3] reported that when using a similar regimen of single-agent HD-MTX, 37 patients exhibited a combined complete response, which was associated with a partial response rate of $29.7 \%$ and a median progression-free survival of 13.7 months. There has since been increasing use of WBRT in the treatment of PCNSL, response-based doses as part of therapy, either with chemotherapy (as in the DeAngelis [25] regimen), or as a consolidation approach per the Italian regimen detailed by Ferreri et al. [28].

There has since been increasing use of WBRT in the treatment of PCNSL, response-based doses as part of therapy, either with chemotherapy (as in the DeAngelis [25] regimen), or as a consolidation approach per the Italian regimen detailed by Ferreri et al. [28].

Treating older patients with PCNSL is challenging as the treatment is palliative in nature and aims to minimize neurotoxicity compared to curative intent in young patients. The use of HD-MTX, which is employed in our study, may require that early WBRT-permitting radiotherapy be deferred until PCNSL progression is eliminated altogether in patients with a likely curative response to first-line therapy. Importantly, current regimens of HD-MTX reflect the optimal responses evident 


\section{Cancer Therapy \& Oncology International Journal}

in other HD-MTX-only regimens; specifically, this approach accelerates the time to a complete response and improves progression-free survival.

These results may define the recommended treatment approach for newly diagnosed PCNSL among patients younger than 60 years old. When treated with this regimen, about onethird of patients relapsed, and salvage therapy often resulted in a durable second remission. With prolonged follow-up, the reported risk of neurotoxicity (26\%) may actually be acceptable to some patients and practitioners, while it may be unacceptable to others. However, data obtained from patients treated with chemotherapy alone suggest that deferring WBRT may significantly compromise disease control. In addition, data from Bessell et al. [29] suggest that lowering the dose of WBRT in young patients who achieve a complete response with chemotherapy compromises both progression-free survival and OS [19]. Therefore, it would seem critical to intensify or alter the chemotherapy regimen in an effort to improve its efficacy, especially if decisions are typically made to defer WBRT in young patients.

Among older patients treated with chemotherapy alone, it is important to note that most died of a progressive tumor. In older patients treated with both chemotherapy and WBRT, the most common cause of death was neurotoxicity. The fact that older patients have identical OS rates, irrespective of whether they receive WBRT as part of their initial therapy, indicates that the impact of treatment-related neurotoxicity and recurrent PCNSL are roughly equivalent. As a result, it is critical to design more effective and less toxic treatment regimens for older PCNSL patients. This is particularly important because patients over 60 years of age comprise at least half of the PCNSL population.

Therefore, if treatment initiation incorporates high-dose MTX, it becomes more effective in the management of PCNSL. In addition, the important role played by radiotherapy in the treatment of this malignancy was confirmed: a higher complete response was observed after radiotherapy than after upfront chemotherapy. Our experience suggests that low-dose WBRT with tumor bed boost after HD-MTX-based chemotherapy is an effective strategy for PCNSL management.

There are a few randomized clinical trials that are currently studying the effect of WBRT with chemotherapy. These include:

NCT00863460: Arm A: MTX-based chemotherapy followed by WBRT 40 Gy. vs. Experimental Arm B: MTX-based chemotherapy followed by intensive chemotherapy and hematopoietic stem cell rescue. At the present time, chemotherapy regimens incorporating HD-MTX are considered part of standard care [30]. In older, patients, PCNSL is associated with increased toxicity $[26,31,32]$. This retrospective study reflects the effects of changes in the various therapeutic strategies leveraged against PCNSL, which have subsequently enhanced survival over the past 15 years, particularly when exploring the impact of chemotherapy as part of first-line treatment against this malignancy. Furthermore, age is an important consideration when determining the most important therapeutic strategy in PCNSL, especially in cases where radiotherapy is administered. There is appreciation for the importance of both quality of life and survival when determining appropriate treatment regimens, particularly among the elderly [20].

The median survival for PCNSL patients treated after 2003 remains low compared to the rate reported in the literature $[8,25]$, but this can be explained by low follow-up rates (25 of 40 patients were still alive at the time of analysis). In this report, we established that trends for improved survival were noted in HDMTX-based treatment approaches among older patients, but it is important to keep in mind that age is a well-known prognostic factor that impacts survival in this disease, with younger ages being associated with greater chance for survival. The results reported here can be explained by the small number of patients included in our study, as well as by the changes in therapeutic strategy that occurred throughout the evaluation period of 15 years.

\section{Conclusion}

Despite the retrospective nature of this study and the small population size, our cohort reflects modifications in therapeutic strategy employed for PCNSL, as well as the associated survival rates, beginning in the early 2000s. This emphasizes that a prospective and collaborative study is needed to collect more accurate data related to the current therapeutic approach, and the associated prognosis, of this rather rare disease. Currently, clinical, imaging, and biological data are being collected through the French National Network, which is dedicated to better understanding PCNSL (otherwise known as the LOC network).

\section{References}

1. Abrey LE, Batchelor TT, Ferreri AJ, Gospodarowicz M, Pulczynski EJ, et al. (2005) International Primary CNS Lymphoma Collaborative Group. Report of an international workshop to standardize baseline evaluation and response criteria for primary CNS lymphoma. J Clin Oncol 23(22): 5034-5043.

2. Bhagavathi S, Wilson JD (2008) Primary central nervous system lymphoma. Arch Pathol Lab Med 132(11): 1830-1834.

3. Herrlinger U, Schabet M, Brugger W, Kortmann RD, Küker W, et al. (2002) German Cancer Society Neuro-Oncology Working Group NOA-03 multicenter trial of single-agent high-dose methotrexate for primary central nervous system lymphoma. Ann Neurol 51(2): 247252.

4. Kadan-Lottick NS, Skluzacek MC, Gurney JG (2002) Decreasing incidence rates of primary central nervous system lymphoma. Cancer 95(1): 193-202.

5. Miller DC, Hochberg FH, Harris NL, Gruber ML, Louis DN, et al. (1994) Pathology with clinical correlations of primary central nervous system non-Hodgkin's lymphoma. The Massachusetts general hospital experience 1958-1989. Cancer 74(4): 1383-1397.

6. Schabet M (1999) Epidemiology of primary CNS lymphoma. J Neuro Oncol 43(3): 199-201.

7. Villano JL, Koshy M, Shaikh H, Dolecek TA, McCarthy BJ (2011) Age, gender, and racial differences in incidence and survival in primary CNS lymphoma. Br J Cancer 105(9): 1414-1418. 


\section{Cancer Therapy \& Oncology International Journal}

8. Daras M, DeAngelis LM (2013) Management of elderly patients with PCNSL. Curr Neurol Neurosci Rep 13(5): 344.

9. Ervin T, Canellos GP (1980) Successful treatment of recurrent primary central nervous system lymphoma with high-dose methotrexate. Cancer 45(7): 1556-1557.

10. Pollack IF, Dade Lunsford L, Flickinger JC, Lee Dameshek H (1989] Prognostic factors in the diagnosis and treatment of primary central nervous system lymphoma. Cancer 63(5): 939-947.

11. Blay JY, Bouhour D, Carrie C, Bouffet E, Brunat-Mentigny M, et al (1995) The C5R protocol: a regimen of high-dose chemotherapy and radiotherapy in primary cerebral non-Hodgkin's lymphoma of patients with no known cause of immunosuppression. Blood 86(8): 2922-2929.

12. Bokstein F, Lossos A, Lossos IS, Siegal T (2002) Central nervous system relapse of systemic non-Hodgkin's lymphoma: results of treatment based on high-dose methotrexate combination chemotherapy. Leuk Lymphoma 43(3): 587-593.

13. DeAngelis LM, Yahalom J, Heinemann MH, Cirrincione C, Thaler HT, et al. (1990) Primary CNS lymphoma combined treatment with chemotherapy and radiotherapy. Neurology 40(1): 80.

14. Skarin AT, Zuckerman KS, Pitman SW, Rosenthal DS, Moloney W, et al. (1977) High-dose methotrexate with folinic acid in the treatment of advanced non-Hodgkin lymphoma including CNS involvement. Blood 50(6): 1039-1047.

15. Schlegel U, Pels H, Oehring R, Blümcke I (1999) Neurologic sequelae of treatment of primary CNS lymphomas. J Neuro Oncol 43(3): 277-286.

16. Thiel E, Korfel A, Martus P, Kanz L, Griesinger F, et al. (2010) Highdose methotrexate with or without whole brain radiotherapy for primary CNS lymphoma (G-PCNSL-SG-1): a phase 3, randomised, noninferiority trial. Lancet Oncol 11(11): 1036-1047.

17. Abrey LE, Yahalom J, DeAngelis LM (2000) Treatment for primary CNS lymphoma: the next step. J Clin Oncol 18(17): 3144-3150.

18. Nayak L, Hedvat C, Rosenblum MK, Abrey LE, DeAngelis LM (2011) Late relapse in primary central nervous system lymphoma: clonal persistence. Neuro Oncol 13(5): 525-529.

19. Kim BH, Kim IH, Park SH, Park CK, Jung HW, et al. (2014) Low-dose whole brain radiotherapy with tumor bed boost after methotrexatebased chemotherapy for primary central nervous system lymphoma. Cancer Res Treat 46(3): 261-269.

20. Lichtman SM (2003) Guidelines for the treatment of elderly cancer patients. Cancer Control 10(6): 445-453.
21. Nelson DF, Martz KL, Bonner H, Nelson JS, Newall J, et al. (1992) Non-Hodgkin's lymphoma of the brain: can high dose, large volume radiation therapy improve survival? Report on a prospective trial by the Radiation Therapy Oncology Group (RTOG): RTOG 8315. Int J Radiat Oncol Biol Phys 23(1): 9-17.

22. Batchelor T, Loeffler JS (2006) Primary CNS lymphoma. J Clin Oncol 24(8): 1281-1288.

23. Freilich RJ, Delattre JY, Monjour A, DeAngelis LM (1996) Chemotherapy without radiation therapy as initial treatment for primary CNS lymphoma in older patients. Neurology 46(2): 435-439.

24. Velasquez WS (1994) Primary central nervous system lymphoma. J Neuro Oncol 20(2): 177-185

25. DeAngelis LM, Seiferheld W, Schold SC, Fisher B, Schultz CJ (2002) Combination chemotherapy and radiotherapy for primary central nervous system lymphoma: Radiation Therapy Oncology Group Study 93-10. J Clin Oncol 20(24): 4643-4648.

26. Phillips EH, Fox CP, Cwynarski K (2014) Primary CNS lymphoma. Curr Hematol Malig Rep 9(3): 243-253.

27. Yahalom J, DeAngelis LM (1994) Primary CNS lymphoma: Long-term results of an intensive combined modality therapy. Int J Radiat Oncol Biol Phys 30: 215.

28. Ferreri AJ, Dell'Oro S, Foppoli M, Bernardi M, Brandes AA, et al. (2006) MATILDE regimen followed by radiotherapy is an active strategy against primary CNS lymphomas. Neurology 66(9): 1435-1438.

29. Bessell EM, Hoang-Xuan K, Ferreri AJ, Reni M (2007) Primary central nervous system lymphoma-biological aspects and controversies in management. Eur J Cancer 43(7): 1141-1152.

30. Ferreri AJ (2011) How I treat primary CNS lymphoma. Blood 118(3): 510-522.

31. Pulczynski EJ, Kuittinen O, Erlanson M, Hagberg H, Fosså A, et al. (2015) Successful change of treatment strategy in elderly patients with primary central nervous system lymphoma by de-escalating induction and introducing temozolomide maintenance: results from a phase II study by the Nordic Lymphoma Group. Haematol Hematol J 100(4): 534-540.

32. Roth P, Martus P, Kiewe P, Möhle R, Klasen H, et al. (2012) Outcome of elderly patients with primary CNS lymphoma in the G-PCNSL-SG-1 trial. Neurology 79(9): 890-896.

This work is licensed under Creative

Commons Attribution 4.0 License

DOI: $10.19080 / C T O I J .2018 .11 .555820$
Your next submission with Juniper Publishers will reach you the below assets

- Quality Editorial service

- Swift Peer Review

- Reprints availability

- E-prints Service

- Manuscript Podcast for convenient understanding

- Global attainment for your research

- Manuscript accessibility in different formats

( Pdf, E-pub, Full Text, Audio)

- Unceasing customer service

Track the below URL for one-step submission

https://juniperpublishers.com/online-submission.php 